\title{
Discussion on the management of University Laboratory
}

\author{
Wei Zhang ${ }^{\mathrm{a}}$, He Pan ${ }^{\mathrm{b}}$, Taihao $\mathrm{Li}^{\mathrm{c}^{\star}}$ \\ Information technology teaching and management center, Jilin Agricultural University, Changchun \\ 130118,China

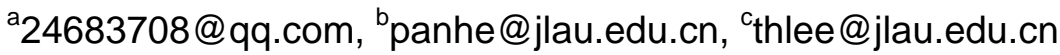

Keywords: Laboratory management; Integrated information system of laboratory management; Information ability

\begin{abstract}
Laboratory management is an important part of teaching and scientific research in Colleges and universities. It is the basic work of campus digital construction. This paper puts forward two kinds of structure models of laboratory management integrated information system based on network environment and the practice of laboratory management in Colleges and universities. The feasibility of the laboratory management system is discussed. Laboratory management integrated information system to pay attention to the construction of software and hardware, so as to promote the improvement of the quality of laboratory management.
\end{abstract}

\section{Introduction}

The most important of modern education theory is to develop students' creative thinking to the maximum extent. Developing students' creative thinking needs to provide a comfortable and relaxed learning environment.This is especially important in engineering colleges ${ }^{[1]}$.The function of university laboratory is no longer a single function of the theory of service, but gradually developed into a comprehensive function of teaching, scientific research, development and so on.Laboratory has become a large-scale, structural synthesis, system complexity, high-grade equipment. University laboratory management information can not only deal with the new requirements of the laboratory management of the current information society, but also can improve the level and efficiency of laboratory management, and provide reliable basis for decision making ${ }^{[2]}$.

\section{The necessity of laboratory management information}

Laboratory management is an important part of teaching and scientific research in Colleges and universities.A large number of data and documents are generated in the process of laboratory management.In the traditional management method, the laboratory management personnel spend a lot of energy and time to collect, organize and complete all kinds of review reports. Laboratory management synthesis information system is established to realize laboratory management of office automation and information, to make full use of the accumulated data, converting it for teaching and scientific research work have guiding value of information resources.Laboratory information management system can provide a higher level of management tools for college teaching and scientific research work ${ }^{[3]}$. It can assist decision-making achieve the goal of school teaching and scientific research.

\section{The important foundation of laboratory management information}

The information flow of laboratory management in Colleges and universities is as follows :(1) Vertical information flow between the upper and lower levels, as the school level teaching units and functional departments, flow to the experimental center (room) information. (2) Lateral information flow, as Information exchange between financial, personnel, educational administration, assets and other functional departments.In order to improve the office efficiency, it is necessary to change the 
traditional manual mode of operation and establish a whole school management information network ${ }^{[4]}$.

In summary, the laboratory management information system can realize the management of laboratory information resources sharing. The laboratory management information network security is an important basis for the improvement of laboratory management ${ }^{[5]}$.

Software selection

The software of the laboratory management information system needs to be a function good according to the University's own development plan and work characteristic. Its operation is simple and easy to develop the management software.

The ideal laboratory management software should have the following characteristics. (1)Users do not need to master the professional knowledge of the computer, as long as the user is familiar with the management work content and process can be in a short period of time to complete the application of the system of independent development. (2)Management system should have the function of managing data, sound, image and so on. (3)The operation of the system is simple, the data link is reliable, the production is rapid, and the development of the system is strong. (4)Source code can be modified at any time according to the user's design ideas for real-time updates.

Structure of information system

Laboratory management integrated information system structure can be based on the University's own laboratory management work content and work flow design. The system has 2 kinds of architecture.

Target subsystem model

The system is planned, designed, adjusted and created on the basis of the original special system of the University. The system combines the management subsystem of personnel, educational administration, finance, scientific research, laboratory management and so on to retain the original relatively independent operation. Under the new interface, the original database of all kinds of subsystems is introduced to form a comprehensive laboratory management information system.

Each subsystem in the system has maintenance (input and modify) module, query module, statistics module, graphics processing and output module. These modules can be achieved by different conditions of query, statistic and output. This system is a dynamic open system, it can be the work of continuous data input, and at any time according to the different requirements of the data can be extended and modified, and constantly improve the better for the decision maker. Advantages are: ensure the independence of the original system, relevant information can be transferred to the different sub database system, the focus of the work of the new system to the subsystem compatible transformation. The disadvantage is that all kinds of data information security will be difficult to guarantee after the database is open.

Module / sub model

This system is based on the laboratory management mode of sub module / content to new planning, design, creation. The system is different from the mentioned in the planning and setting of the module, and other functions have no essential difference.

The system is a special management system, so it is suitable for people who are familiar with the laboratory management process. The new system may be linked to the original system database link is not smooth or cannot be linked to the situation, part of the information needs to be through different systems to achieve the integrity and retention of information between different systems.

Set up dedicated server

The laboratory management information system should establish a dedicated server to access the campus network in order to ensure the data security and data maintenance and management. Software is running on the server side. The data is also stored in the server with WWW mode of information release function. Customers can enter the specified page through the browser according to the set permissions to achieve the management of laboratory information data browsing, input, modify and query. Table and data are downloaded and uploaded via file transfer (FTP). Open to the public information can be directly related to the page to get access. The information and the table 
cannot be published which can be logged on and download through the host account and password authentication.

\section{Improve the management level}

Laboratory management personnel need to continuously improve the skills and quality with the development of laboratory management information. Laboratory management information system should achieve the following points. (1) Need to break the old idea and the conversion of new thinking. The laboratory of Engineering University was the main place to complete the teaching experiment and the teachers' scientific research. Laboratory management level directly affects the quality of experimental teaching and scientific research work. (2) Laboratory management personnel should be equipped with a certain computer, network and information technology knowledge of compound talents ${ }^{[6]}$. (3) Need a management mechanism and strategy to mobilize the enthusiasm of laboratory management personnel. Take the following measure to realize the information of laboratory management.

Leadership attention is an important prerequisite and guarantee for the smooth implementation of laboratory management information work. Laboratory management information involves a wide range, the leadership of the decision-making is very critical. The construction of computer and network hardware in laboratory environment is the premise and guarantee to make full use of the existing network information resources. Training laboratory management personnel to master new technology and skilled operation of new equipment is to strengthen the construction of the fundamental.

\section{Conclusions}

When the network of the university laboratory management information construction is discussed, it's no longer a new thing. It's just a basic technology application in twenty-first Century. One of the information nodes in the information society is the construction of Digital Campus. The construction of information management system of laboratory should pay attention to the importance of the unified planning and construction stages in the process of network security and the special system compatibility. The construction of the laboratory management synthesis information system can not only make full use of network information resources of campus network has been, but also improve laboratory management personnel using new technology to obtain new information skills, strengthen the ability of information management of the laboratory management personnel training.

\section{Reference}

[1] Wang Z L, Liu L, Cui M. Laboratory Teaching and Management in Colleges and Universities[J]. Journal of Nanjing College Population Program Management, 2005.

[2] Sandlin C S, Johnson R C, Swaim L, et al. Laboratory Information Management System for Emergency Response: Validation and Quality Assurance of Analytical Methodologies[J]. Journal of the Association for Laboratory Automation, 2009, 14(3):126-132.

[3] Blair F A, Arritt J M, Lundy L J. Analytical Laboratory Information Management System (ALIMS)[J]. Astm Special Technical Publication, 1985(944):11.

[4] Tang T. Analyze and Design of University Computer Laboratory Management Information System[J]. Computer Knowledge \& Technology, 2011.

[5] Huang Z Q, Chen D J, Peng S J. Design and Implementation of the Management Information System of House in the University Laboratory[J]. Experiment Science \& Technology, 2006.

[6] Ding S D. Discussion on the Quality of Universities Laboratory's Specialized Technical Management Personnel and the Sci-tech Information Service[J]. Sci-Tech Information Development \& Economy, 2006. 